\title{
A pan-African high-resolution drought index dataset
}

\author{
Jian Peng ${ }^{1,2}$, Simon Dadson $^{1}$, Feyera Hirpa ${ }^{1}$, Ellen Dyer $^{1}$, Thomas Lees ${ }^{1}$, Diego G. Miralles ${ }^{3}$, \\ Sergio M. Vicente-Serrano ${ }^{4}$, and Chris Funk ${ }^{5,6}$ \\ ${ }^{1}$ School of Geography and the Environment, University of Oxford, OX1 3QY Oxford, UK \\ ${ }^{2}$ Max Planck Institute for Meteorology, Hamburg, Germany \\ ${ }^{3}$ Hydro-Climatic Extremes Lab (H-CEL), Ghent University, Ghent, Belgium \\ ${ }^{4}$ Instituto Pirenaico de Ecología, Consejo Superior de Investigaciones Científicas (IPE-CSIC) Zaragoza, Spain \\ ${ }^{5}$ U.S. Geological Survey, Earth Resources Observation and Science Center, Sioux Falls, South Dakota, USA \\ ${ }^{6}$ Santa Barbara Climate Hazards Center, University of California, Santa Barbara, USA
}

Correspondence: Jian Peng (jian.peng@ouce.ox.ac.uk)

Received: 8 August 2019 - Discussion started: 7 October 2019

Revised: 22 January 2020 - Accepted: 22 February 2020 - Published: 31 March 2020

\begin{abstract}
Droughts in Africa cause severe problems, such as crop failure, food shortages, famine, epidemics and even mass migration. To minimize the effects of drought on water and food security on Africa, a highresolution drought dataset is essential to establish robust drought hazard probabilities and to assess drought vulnerability considering a multi- and cross-sectional perspective that includes crops, hydrological systems, rangeland and environmental systems. Such assessments are essential for policymakers, their advisors and other stakeholders to respond to the pressing humanitarian issues caused by these environmental hazards. In this study, a high spatial resolution Standardized Precipitation-Evapotranspiration Index (SPEI) drought dataset is presented to support these assessments. We compute historical SPEI data based on Climate Hazards group InfraRed Precipitation with Station data (CHIRPS) precipitation estimates and Global Land Evaporation Amsterdam Model (GLEAM) potential evaporation estimates. The high-resolution SPEI dataset (SPEI-HR) presented here spans from 1981 to 2016 (36 years) with $5 \mathrm{~km}$ spatial resolution over the whole of Africa. To facilitate the diagnosis of droughts of different durations, accumulation periods from 1 to 48 months are provided. The quality of the resulting dataset was compared with coarse-resolution SPEI based on Climatic Research Unit (CRU) Time Series (TS) datasets, Normalized Difference Vegetation Index (NDVI) calculated from the Global Inventory Monitoring and Modeling System (GIMMS) project and root zone soil moisture modelled by GLEAM. Agreement found between coarse-resolution SPEI from CRU TS (SPEI-CRU) and the developed SPEI-HR provides confidence in the estimation of temporal and spatial variability of droughts in Africa with SPEI-HR. In addition, agreement of SPEI-HR versus NDVI and root zone soil moisture - with an average correlation coefficient $(R)$ of 0.54 and 0.77 , respectively - further implies that SPEI-HR can provide valuable information for the study of drought-related processes and societal impacts at sub-basin and district scales in Africa. The dataset is archived in Centre for Environmental Data Analysis (CEDA) via the following link: https://doi.org/10.5285/bbdfd09a04304158b366777eba0d2aeb (Peng et al., 2019a).
\end{abstract}




\section{Introduction}

Drought is a complex phenomenon that affects natural environments and socioeconomic systems in the world (von Hardenberg et al., 2001; Vicente-Serrano, 2007; Van Loon, 2015; Wilhite and Pulwarty, 2017). Impacts include crop failure, food shortage, famine, epidemics and even mass migration (Wilhite et al., 2007; Ding et al., 2011; Zhou et al., 2018). In recent years, severe events have occurred across the world, such as the 2003 central Europe drought (GarcíaHerrera et al., 2010), the 2010 Russian drought (Spinoni et al., 2015), the 2011 Horn of Africa drought (Nicholson, 2014), the 2000 drought in southeastern Australia (van Dijk et al., 2013; Peng et al., 2019c), the 2013-2014 California drought (Swain et al., 2014), the 2014 North China drought (Wang and He, 2015) and the 2015-2017 southern Africa drought (Baudoin et al., 2017; Muller, 2018). Widespread negative effects of these droughts on natural and socioeconomic systems have been reported afterwards (Wegren, 2011; Arpe et al., 2012; Griffin and Anchukaitis, 2014; Mann and Gleick, 2015; Dadson et al., 2019; Marvel et al., 2019). Thus, there is a clear need to improve our knowledge about the spatial and temporal variability of drought, which provides a basis for quantifying drought impacts and the exposure of society, the economy, and the environment over different areas and timescales (Pozzi et al., 2013; AghaKouchak et al., 2015).

Generally, drought is defined as a temporal anomaly characterized by a deficit of water compared with long-term conditions (Mishra and Singh, 2010; Van Loon, 2015). Droughts can typically be grouped into five types: meteorological (precipitation deficiency), agricultural (soil moisture deficiency), hydrological (runoff and/or groundwater deficiency), socioeconomic (social response to water supply and demand) and environmental or ecologic (Keyantash and Dracup, 2002; AghaKouchak et al., 2015; Crausbay et al., 2017). These different drought categories involve different event characteristics in terms of timing, intensity, duration and spatial extent, making it very difficult to characterize droughts quantitatively (Panu and Sharma, 2002; LloydHughes, 2014; Vicente-Serrano, 2016). For this reason numerous drought indices have been proposed for precise applications, and reviews of the available indices have been provided by previous studies, such as Heim Jr. (2002), Keyantash and Dracup (2002), and Mukherjee et al. (2018). Van Loon (2015) noted that there is no best drought index for all types of droughts because every index is designed for a specific drought type, thus multiple indices are required to capture the multifaceted nature of drought. Nevertheless, the Standardized Precipitation Index (SPI) is recommended by the World Meteorological Organization (WMO) for drought monitoring, which is calculated based solely on long-term precipitation data over different time spans (McKee et al., 1993). The advantages of SPI are its relative simplicity and its ability to characterize different types of droughts given the different times of response of different usable water sources to precipitation deficits (Kumar et al., 2016; Zhao et al., 2017). However, information on precipitation is inadequate to characterize drought; in most definitions, drought conditions also depend on the demand of water vapour from the atmosphere. More recently, Vicente-Serrano et al. (2010) proposed an alternative drought index for SPI, which is called Standardized Precipitation Evapotranspiration Index (SPEI). Compared to SPI, it considers not only the precipitation supply but also the atmospheric evaporative demand (Beguería et al., 2010; Vicente-Serrano et al., 2012b). This makes the index more informative of the actual drought effects over various natural systems and socioeconomic sectors (VicenteSerrano et al., 2012b; Bachmair et al., 2016, 2018; Kumar et al., 2016; S. Sun et al., 2016, 2018; Peña-Gallardo et al., 2018a, b).

For the calculation of SPEI, high-quality and long-term observations of precipitation and atmospheric evaporative demand are necessary. These observations may either come from ground-based station data or gridded data, such as satellite and reanalysis datasets. For example, the SPEIbase (Beguería et al., 2010) and the Global Precipitation Climatology Centre Drought Index (GPCC-DI) (Ziese et al., 2014) both provide SPEI datasets at a global scale. SPEIbase provides gridded SPEI with a $50 \mathrm{~km}$ spatial resolution and is calculated from Climatic Research Unit (CRU) Time Series (TS) datasets, which are produced based on measurements from more than 4000 ground-based weather stations across the world (Harris et al., 2014). The SPEI dataset provided by GPCC-DI has a spatial resolution of $1^{\circ}$ and was generated from GPCC precipitation (Becker et al., 2013; Schneider et al., 2016) and National Oceanic and Atmospheric Administration (NOAA)'s Climate Prediction Center (CPC) temperature dataset (Fan and Van den Dool, 2008). Both of these datasets have been applied for various drought-related studies at global and regional scales (e.g. Chen et al., 2013; Vicente-Serrano et al., 2013, 2016; Isbell et al., 2015; Q. Sun et al., 2016; Deo et al., 2017). However, these global SPEI datasets' spatial resolution are too coarse to be applied at district or sub-basin scales (Vicente-Serrano et al., 2017). A sub-basin-scale quantification of drought conditions is particularly crucial in regions such as Africa, in which geospatial data and drought indices can be essential to manage existing drought-related risks (Vicente-Serrano et al., 2012a) and where in situ measurements are scarce (Trambauer et al., 2013; Masih et al., 2014; Anghileri et al., 2019). Over last century, Africa has been severely influenced by intense drought events, which has led to food shortages and famine in many countries (Anderson et al., 2012; Yuan et al., 2013; Sheffield et al., 2014; Awange et al., 2016; Funk et al., 2018; Nicholson, 2018; Gebremeskel et al., 2019). Therefore, the availability of a high-resolution drought index dataset may contribute to an improved characterization of drought risk and vulnerability and minimize its impact on water and food security by supporting policymakers, water managers and 
stakeholders. Conveniently, with the advancement of satellite technology, the estimation of precipitation and evaporation from remote sensing datasets is becoming more accurate (Fisher et al., 2017). In particular, the long-term Climate Hazards group InfraRed Precipitation with Station data (CHIRPS) (Funk et al., 2015a) precipitation dataset and Global Land Evaporation Amsterdam Model (GLEAM) (Miralles et al., 2011) evaporation dataset provide high-quality data for near-real-time drought monitoring. Here, we use CHIRPS and GLEAM datasets to develop a pan-African high spatial resolution $(5 \mathrm{~km})$ SPEI dataset, which may be useful to inform drought relief management strategies for the continent. The dataset covers the period from 1981 to 2016 and it is comprehensively inter-compared with soil moisture, vegetation index and coarse-resolution SPEI datasets.

\section{Data and methodology}

\subsection{Data}

\subsubsection{CHIRPS}

CHIRPS is a recently developed high-resolution daily, pentadal, dekadal and monthly precipitation dataset (Funk et al., 2015a). It was produced by blending a set of satelliteonly precipitation values (CHIRP) with additional monthly and pentadal station observations. CHIRP is based on infrared cold cloud duration (CCD) estimates calibrated with the Tropical Rainfall Measuring Mission Multi-satellite Precipitation Analysis version 7 (TMPA 3B42 v7) and the Climate Hazards group Precipitation climatology (CHPclim). $\mathrm{CHP}_{\text {clim }}$ (Funk et al., 2015a, b) is based on station data from the Food and Agriculture Organization (FAO) and the Global Historical Climate Network (GHCN). Compared with other global precipitation datasets, such as Multi-Source Weighted-Ensemble Precipitation (MSWEP) (Beck et al., 2017) and Global Precipitation Climatology Project (GPCP) (Adler et al., 2003), CHIRPS has several advantages: a long period of record, high spatial resolution $(5 \mathrm{~km})$, low spatial biases and low temporal latency. It has been widely validated and applied in various applications (e.g. Shukla et al., 2014; Maidment et al., 2015; Duan et al., 2016; ZambranoBigiarini et al., 2017; Rivera et al., 2018). In particular, it was recently validated over East Africa and Mozambique and demonstrated good performance compared to other precipitation datasets (Toté et al., 2015; Dinku et al., 2018). Furthermore, CHIRPS was specifically designed for drought monitoring over regions with deep convective precipitation, scarce observation networks and complex topography (Funk et al., 2014). Several studies (e.g. Toté et al., 2015; Guo et al., 2017) have used CHIRPS for drought monitoring. Its high spatial resolution makes it particularly suitable for local-scale studies, such as sub-basin drought monitoring, especially in areas with complex topography. The detailed description of the
Table 1. Categories of dry and wet conditions indicated by SPEI values.

\begin{tabular}{ll}
\hline SPEI & Category \\
\hline 2 and above & Extremely wet \\
1.5 to 1.99 & Very wet \\
1.0 to 1.49 & Moderately wet \\
-0.99 to 0.99 & Near Normal \\
-1.0 to -1.49 & Moderately dry \\
-1.5 to -1.99 & Severely dry \\
-2 and less & Extremely dry \\
\hline
\end{tabular}

dataset was provided by Funk et al. (2015a). In this study, daily CHIRPS precipitation from 1981 to 2016 was used.

\subsubsection{GLEAM}

GLEAM is designed to estimate land surface evaporation and root zone soil moisture from remote sensing observations and reanalysis data (Miralles et al., 2011; Martens et al., 2017). Specifically, the Priestley-Taylor equation is used to calculate potential evaporation within GLEAM based on near-surface temperature and net radiation, while the root zone soil moisture is obtained from a multilayer water balance driven by precipitation observations and updated with microwave soil moisture estimates (Martens et al., 2017). The actual evaporation is estimated by constraining potential evaporation with a multiplicative evaporative stress factor based on root zone soil moisture and vegetation optical depth (VOD) estimates. GLEAM version 3a (v3a) provides global daily potential and actual evaporation, evaporative stress conditions, and root zone soil moisture from 1980 to 2018 at spatial resolution of $0.25^{\circ}$ (Martens et al., 2017) (see http://www.gleam.eu, last access: 29 March 2020). GLEAM datasets have already been comprehensively evaluated against FLUXNET observations and used for multiple hydro-meteorological applications (Greve et al., 2014; Miralles et al., 2014; Trambauer et al., 2014; Forzieri et al., 2017; Lian et al., 2018; Richard et al., 2018; Vicente-Serrano et al., 2018; Zhan et al., 2019). In particular, two recent studies detected global drought conditions based on GLEAM potential and actual evaporation data (Vicente-Serrano et al., 2018; Peng et al., 2019b). For this study, the GLEAM potential evaporation and root zone soil moisture were used.

\subsubsection{CRU-TS}

The global gridded CRU-TS datasets provide most widely used climate variables, including precipitation, potential evaporation, diurnal temperature range, maximum and minimum temperature, mean temperature, frost day frequency, cloud cover, and vapour pressure (Harris et al., 2014). The CRU TS datasets were produced using angular distance weighting (ADW) interpolation based on monthly mete- 

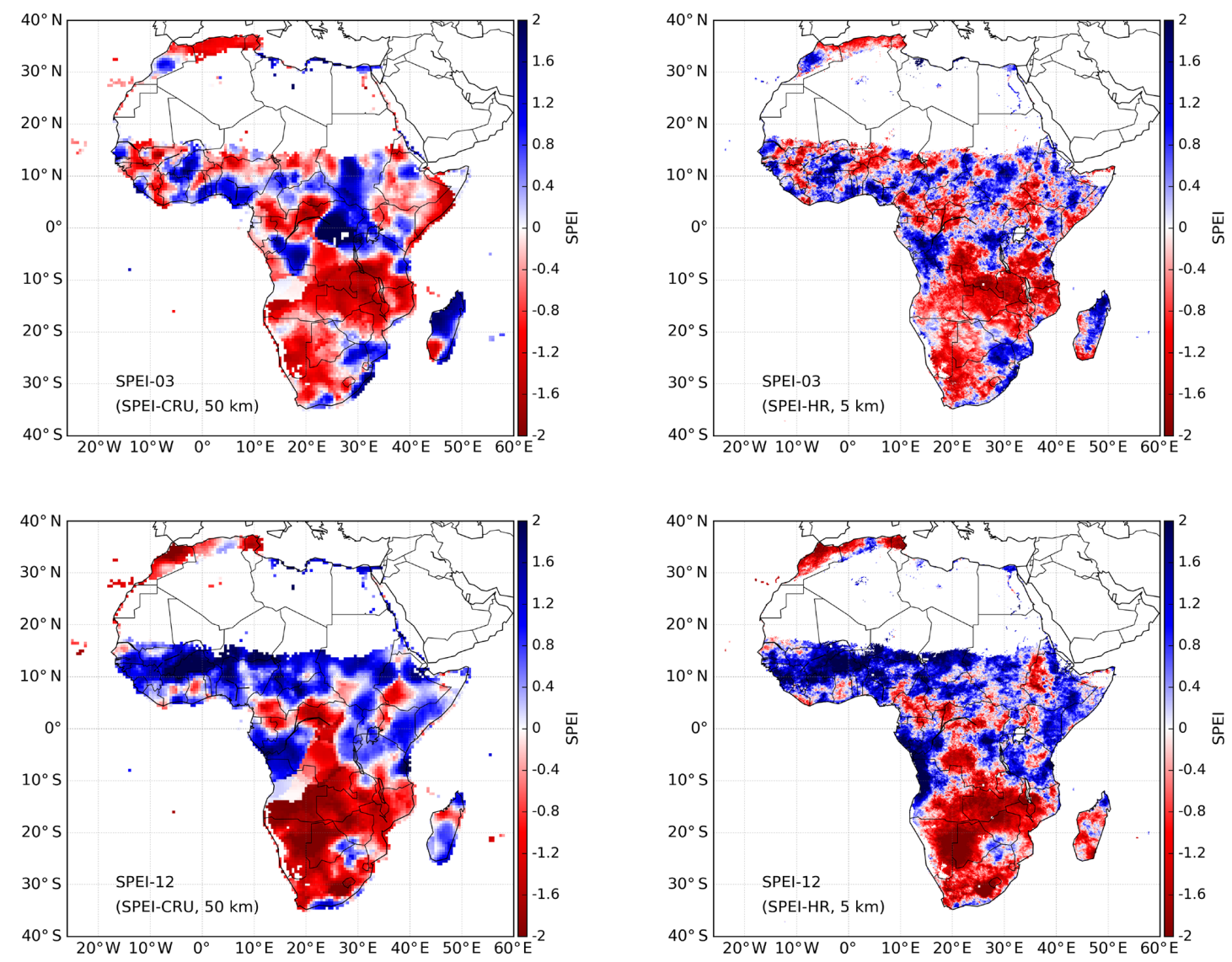

Figure 1. Spatial patterns of 3-month and 12-month SPEI at high spatial resolution (5 km) and coarse spatial resolution (50 km) in June 1995. The high spatial resolution SPEI (SPEI-HR) is based on CHIRPS precipitation and GLEAM potential evaporation, while the coarse spatial resolution SPEI (SPEI-CRU) is calculated from CRU TS datasets.

orological observations collected at ground-based stations across the world. The recently released CRU TS version 4.0.1 covers the period 1901-2016 and provides monthly data at $50 \mathrm{~km}$ spatial resolution. The CRU TS datasets have been widely used for various applications since their release (e.g. van der Schrier et al., 2013; Chadwick et al., 2015; Delworth et al., 2015; Jägermeyr et al., 2016). The SPEIbase dataset was generated from CRU TS datasets (Beguería et al., 2010). In this study, the CRU TS precipitation and potential evaporation from 1981 to 2016 was used.

\subsubsection{GIMMS NDVI}

The Normalized Difference Vegetation Index (NDVI) can serve as a proxy of vegetation status and has been widely applied to investigate the effects of drought on vegetation (e.g. Rojas et al., 2011; Vicente-Serrano et al., 2013, 2018; Törnros and Menzel, 2014). The Global Inventory Monitoring and Modeling System (GIMMS) NDVI was generated based on Advanced Very-High-Resolution Radiometer (AVHRR) observations and has accounted for various deleterious effects, such as orbital drift, calibration loss and volcanic eruptions
(Beck et al., 2011; Pinzon and Tucker, 2014). For the current study, the latest version of GIMMS NDVI (3g.v1) was used, which covers the time period from 1981 to 2015 at biweekly temporal resolution and $8 \mathrm{~km}$ spatial resolution (Pinzon and Tucker, 2014).

\subsection{Methods}

\subsubsection{SPEI calculation}

The SPEI proposed by Vicente-Serrano et al. (2010) has been used for a wide variety of agricultural, ecological and hydrometeorological applications (e.g. Schwalm et al., 2017; Naumann et al., 2018; Jiang et al., 2019). It accounts for the impacts of evaporation demand on droughts and inherits the simplicity and multi-temporal characteristics of SPI. The procedure for SPEI calculation includes the estimation of a climatic water balance (namely the difference between precipitation and potential evaporation), the aggregation of the climatic water balance over various timescales (e.g. 1, 3, 6, 12,24 months or more) and a fitting to a certain parameter distribution. As suggested by Beguería et al. (2014) and Vicente-Serrano and Beguería (2016), the log-logistic proba- 

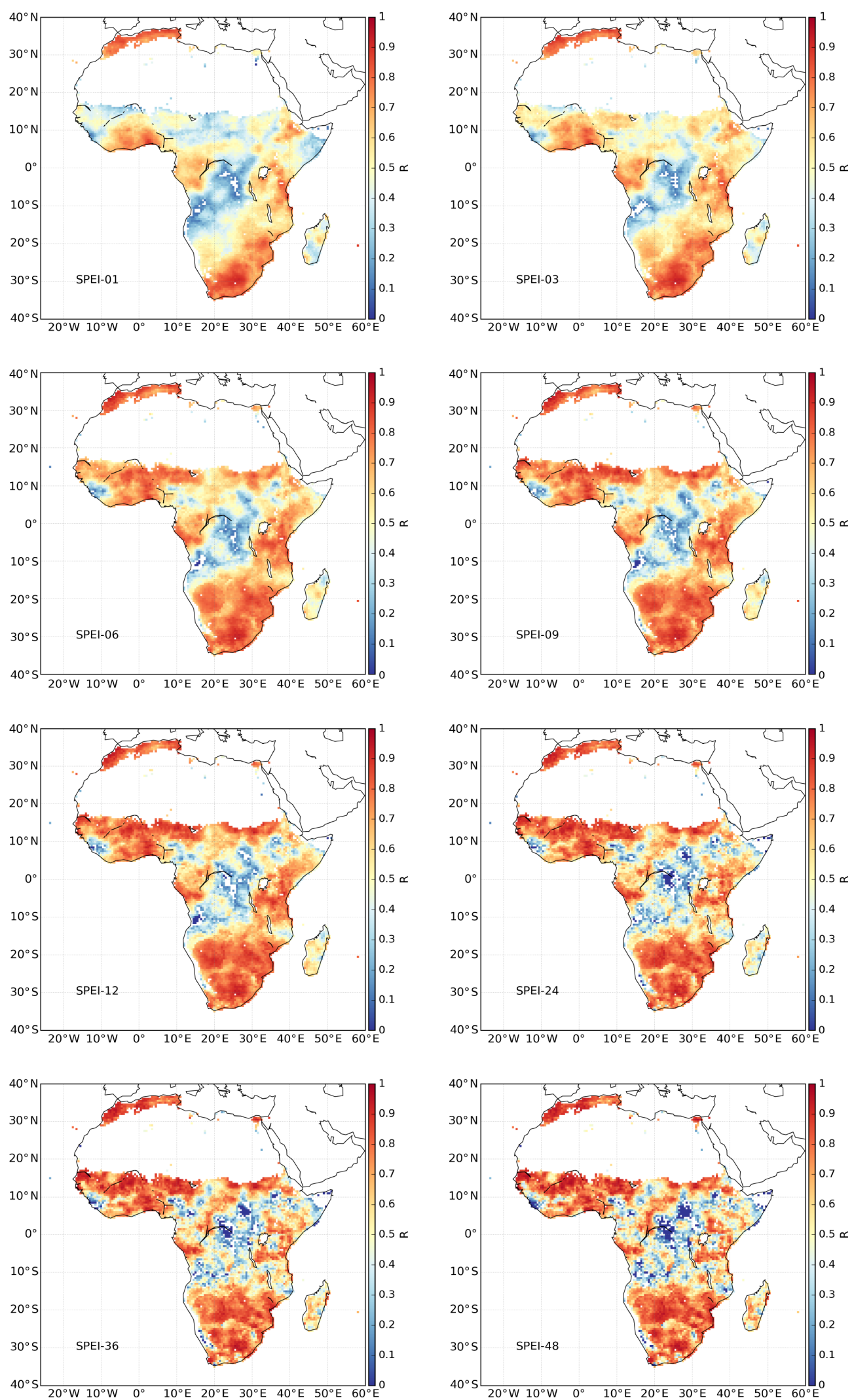

Figure 2. Correlation $(p<0.05)$ between SPEI-HR and SPEI-CRU, with the number indicating different months. 


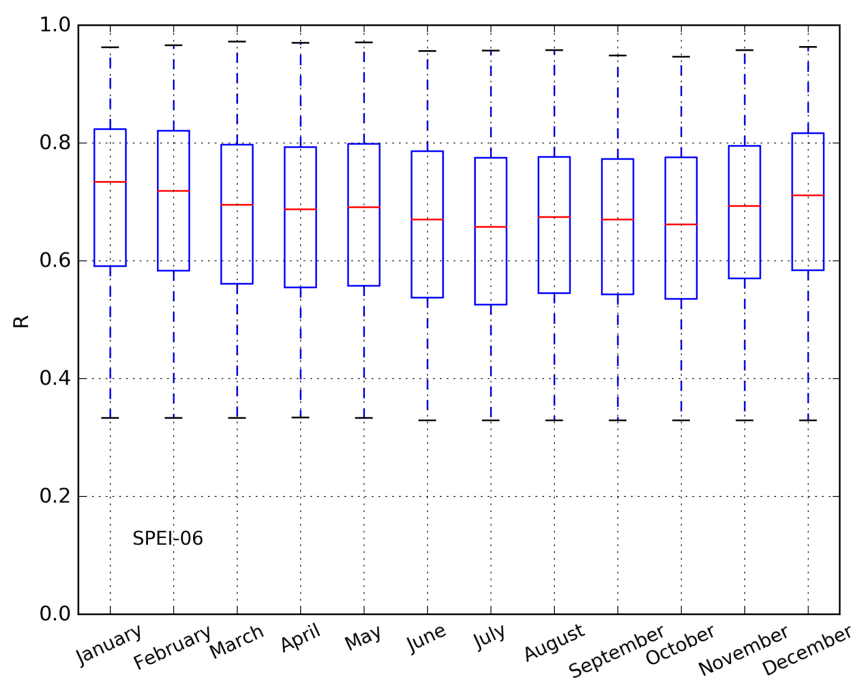

Figure 3. Box plot of the correlation $(p<0.05)$ between SPEI-HR and SPEI-CRU for each month of the entire record. The results here are based on 6-month SPEI, and the red line in each box represents the median.

bility distribution is best for SPEI calculation, from which the probability distribution of the difference between precipitation and potential evaporation can be calculated as suggested by Vicente-Serrano et al. (2010) and Beguería et al. (2014). The negative and positive SPEI values indicate dry and wet conditions, respectively. Table 1 summarizes the category of dry and wet conditions based on SPEI values. In this study, the CHIRPS and GLEAM datasets were used for SPEI calculation at high spatial resolution $(5 \mathrm{~km})$. For comparison, the SPEI at $50 \mathrm{~km}$ was also calculated based on CRU TS datasets for the same 1981-2016 period. It should be noted that the SPEI over sparsely vegetated and barren areas were masked out based on the Moderate Resolution Imaging Spectroradiometer (MODIS) land cover product (MCD12Q1) (Friedl et al., 2010) because SPEI is not reliable over these areas (Beguería et al., 2010, 2014; Zhao et al., 2017).

\subsubsection{Evaluation criteria}

The SPEIbase dataset (Beguería et al., 2010) was calculated with CRU TS dataset, which has been evaluated and applied by many studies (e.g. Chen et al., 2013; Vicente-Serrano et al., 2013; Isbell et al., 2015; Q. Sun et al., 2016; Greenwood et al., 2017; Um et al., 2017). The newly generated SPEI at high spatial resolution based on CHIRPS and GLEAM (SPEI-HR) is compared temporally and spatially to the SPEI calculated from CRU TS datasets. In addition, the NDVI can also serve as an indicator for drought and vegetation health and to assess the performance of drought indices (VicenteSerrano et al., 2013; Aadhar and Mishra, 2017). Furthermore, root zone soil moisture is an ideal hydrological variable for agricultural (soil moisture) drought monitoring. The recently released root zone soil moisture (RSM) from GLEAM v3 provides a great opportunity to evaluate whether soil moisture drought is well represented by SPEI. To facilitate direct comparison between SPEI, NDVI and RSM, both NDVI and RSM are standardized by subtracting their corresponding (1981-2016) mean and expressed the resulting anomalies as numbers of standard deviations. This standardization has been applied by many studies to evaluate drought indices (Anderson et al., 2011; Mu et al., 2013; Zhao et al., 2017). The correlation between SPEI and the standardized NDVI and RSM is quantified using Pearson's correlation coefficient $(R)$. In addition, the high-resolution SPEI from GLEAM and CHIRPS is also resampled to the same grid size of SPEI from CRU TS in order to quantify their correlation and disentangle whether the added value of the former arises from its increased accuracy or higher resolution. In the following section, the high-resolution $(5 \mathrm{~km})$ SPEI is referred to as SPEI$\mathrm{HR}$, while the coarse $50 \mathrm{~km}$ resolution SPEI is referred to as coarse spatial resolution SPEI (SPEI-CRU).

\section{Results and discussion}

\subsection{Inter-comparison between high- and coarse-resolution SPEI}

Figure 1 shows the spatial distribution of SPEI-HR and SPEI-CRU at different resolutions for an example month (June 1995). Figure 1a, b show the 3-month SPEI and 12month SPEI, respectively. It can be seen that the highresolution and coarse-resolution SPEI display quite similar dry and wet patterns over the whole of Africa for both temporal scales. However, as expected, the SPEI-HR shows much more spatial detail that, as a result, reflects mesoscale geographic and climatic features, which highlights the advantages of this new dataset. The differences in patterns between 3-month and 12-month SPEI indicate the different water deficits caused by different aggregation timescales, which can further separate agricultural, hydrological, environmental and other droughts. For example, in June 1995, southern Africa showed persistent dry conditions over a prolonged period, while western Africa only showed a short-term drought.

In order to quantify how different SPEI-HR is from SPEI$\mathrm{CRU}$, the correlation between them is calculated for each grid cell over the whole study period. Figure 2 shows the correlations for timescales 1, 3, 6, 9, 12, 24, 36 and 48 months. In general, the SPEI-HR and SPEI-CRU agree well in terms of temporal variability with high positive correlations over most of Africa for every timescale. However, relatively low correlations appear in central Africa, and they become lower as the SPEI timescale increases. This region has very few station observations. It should be noted that the correlations shown here are statistically significant, with $p$ values of less than 0.05 . In addition, the average correlation between 6 month SPEI-CRU and SPEI-HR for each month of the year is summarized in Fig. 3 using a box plot. In general, pos- 


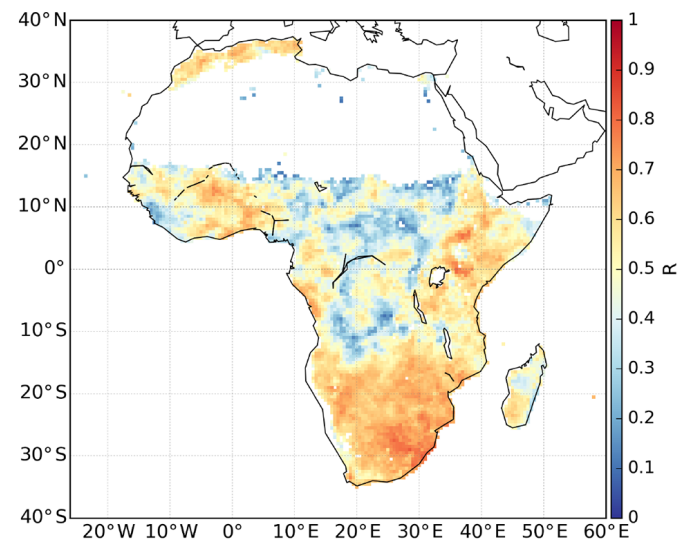

(a)

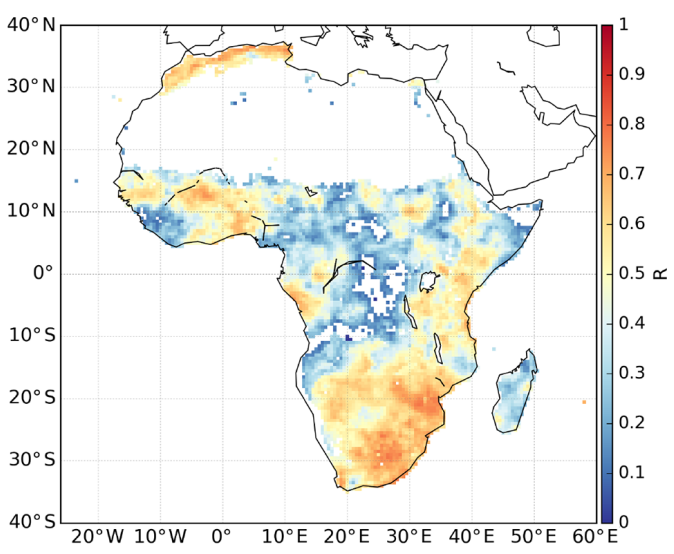

(b)

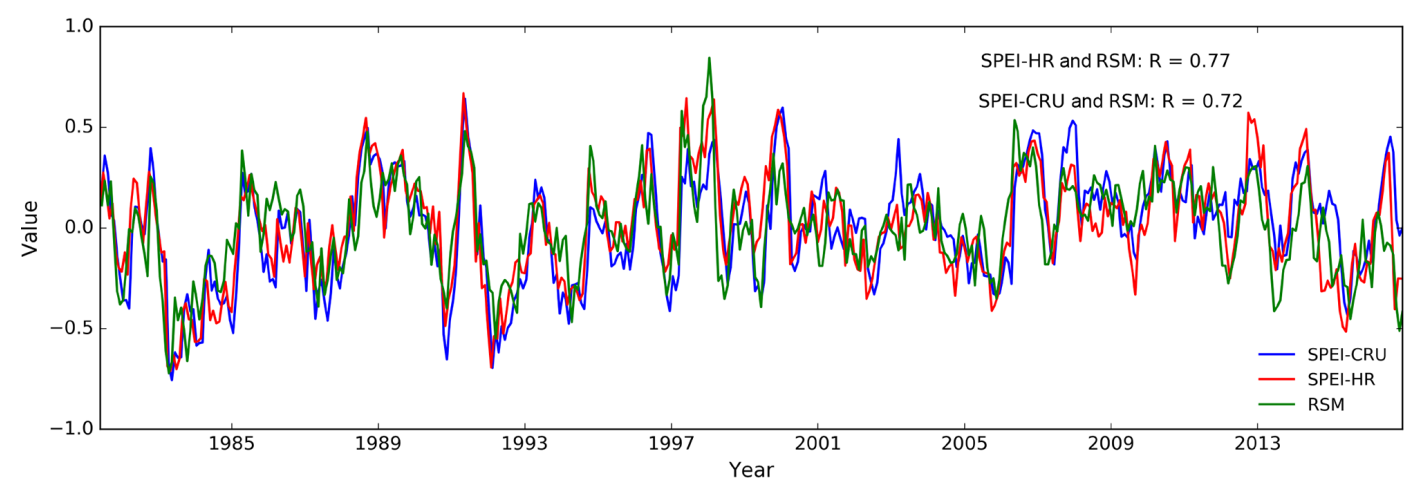

(c)

Figure 4. Spatial maps of correlation between SPEI and root zone soil moisture (RSM) for 6-month SPEI: (a) SPEI-HR and (b) SPEI-CRU. The time series of the African area mean RSM and SPEI are shown in (c), where $R$ refers to the correlation coefficient. The correlations shown here are all significant at the $95 \%$ confidence level.

Table 2. The correlation $(p<0.05)$ between area mean RSM and SPEI at different timescales.

\begin{tabular}{lrrrrrrrr}
\hline & SPEI-01 & SPEI-03 & SPEI-06 & SPEI-09 & SPEI-12 & SPEI-24 & SPEI-36 & SPEI-48 \\
\hline$R$ (SPEI-CRU) & 0.52 & 0.74 & 0.72 & 0.64 & 0.56 & 0.41 & 0.26 & 0.16 \\
$R$ (SPEI-HR) & 0.49 & 0.76 & 0.77 & 0.69 & 0.62 & 0.44 & 0.29 & 0.18
\end{tabular}

itive correlations with a median larger than $0.6(p<0.05)$ are found for every month. There are no substantial differences in correlations between different months. Figure A1 in Appendix shows additional box plots for SPEI at other timescales.

\subsection{Comparison against root zone soil moisture and NDVI}

To gain more insights into their significance and applicability, the SPEI datasets are compared with NDVI and RSM. Figure 4 shows the results of the spatial and temporal comparison between 6-month SPEI and RSM as indicated by Törnros and Menzel (2014). Figure 4a, b display the correlation $(p<0.05)$ of SPEI-HR and SPEI-CRU against RSM during the whole time period, respectively. In general, both SPEI-HR and SPEI-CRU show strong correlations with RSM over the whole African continent. Compared to SPEI-CRU, the SPEI-HR shows higher correlations, particularly over central Africa. Since Sect. 3.1 shows that relatively large discrepancy between SPEI-CRU and SPEI-HR exists over central Africa, the results presented here suggest a potentially better performance of SPEI-HR compared with SPEI-CRU in this region.

The time series of SPEI and RSM, averaged over the entire study area, are shown in Fig. 4c, together with the corresponding correlations. It can be seen that both SPEI-HR and SPEI-CRU agree well with each other and with the RSM dynamics. Consistent with the results from the spatial correlation analysis, the SPEI-HR and SPEI-CRU show simi- 


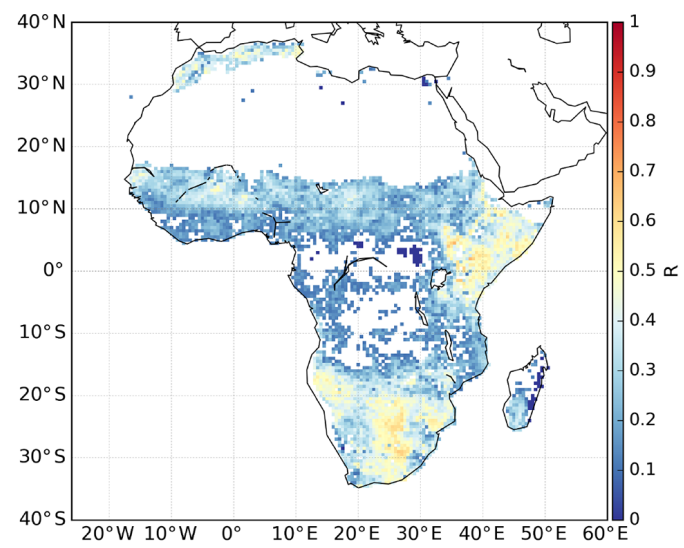

(a)

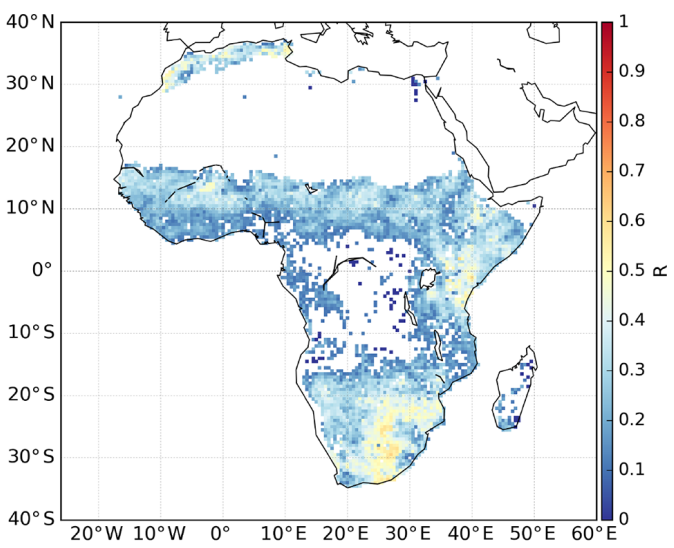

(b)

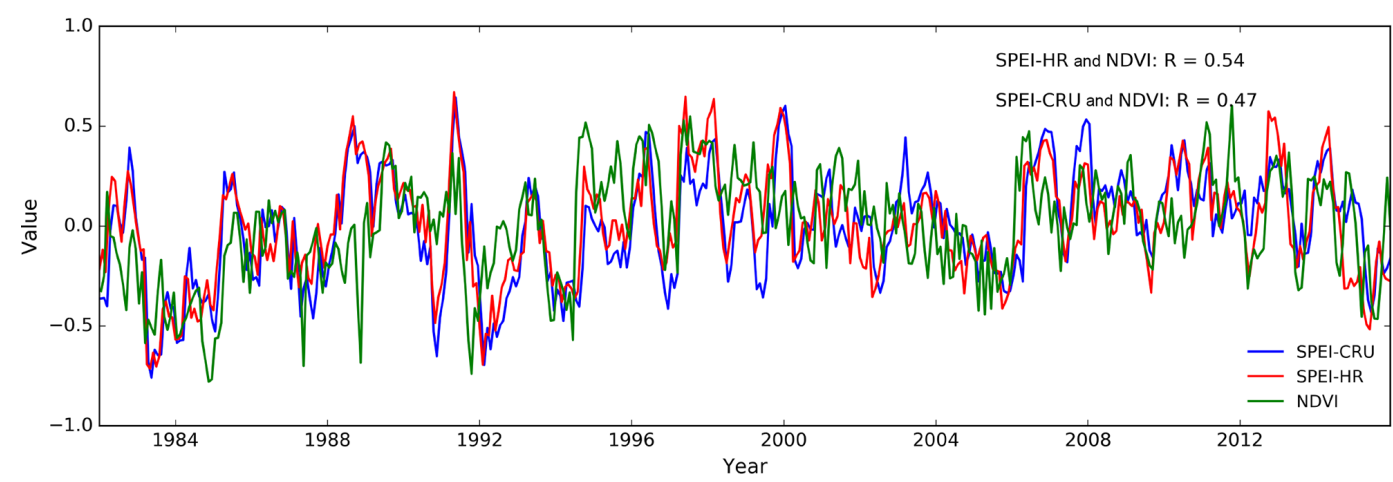

(c)

Figure 5. Spatial maps of the correlation between SPEI and NDVI for 6-month SPEI: (a) SPEI-HR and (b) SPEI-CRU. The time series of area mean NDVI and SPEI are shown in (c), where $R$ refers to the correlation coefficient. The correlations shown here are all significant at the $95 \%$ confidence level.

Table 3. The correlation $(p<0.05)$ between area mean NDVI and SPEI at different timescales.

\begin{tabular}{lrrrrrrrr}
\hline & SPEI-01 & SPEI-03 & SPEI-06 & SPEI-09 & SPEI-12 & SPEI-24 & SPEI-36 & SPEI-48 \\
\hline$R$ (SPEI-CRU) & 0.23 & 0.42 & 0.47 & 0.48 & 0.47 & 0.50 & 0.34 & 0.20 \\
$R$ (SPEI-HR) & 0.31 & 0.51 & 0.54 & 0.56 & 0.57 & 0.57 & 0.44 & 0.29 \\
\hline
\end{tabular}

lar results when compared with RSM ( $R=0.77$ for SPEIHR; $R=0.72$ for SPEI-CRU). Furthermore, the scatter plots between 6-month SPEI and RSM for the entire data record are shown in Appendix Fig. A2, where positive and significant correlations with RSM are found for both SPEI-HR $(R=0.51)$ and SPEI-CRU $(R=0.42)$. To explore the correlation between RSM and different timescales of SPEI, Table 2 summarizes the correlation value calculated in the same way as Fig. 4c. It can be seen that the highest correlations against RSM are found at 3- and 6-month timescales. It should be noted that satellite-data-driven estimates of root zone soil moisture are more suitable for evaluating SPEI compared to satellite-based top-layer soil moisture or reanalysis soil moisture data (Mo et al., 2011; Xu et al., 2018).
Similar to the above analysis between SPEI and RSM, the comparison of results between SPEI and NDVI is shown in Fig. 5. First, Fig. 5a, b present the spatial distribution of the correlations $(p<0.05)$ between SPEI-HR and NDVI and between SPEI-CRU and NDVI, respectively. While correlations are overall lower than for RSM, it can be seen that both SPEI datasets are positively correlated with NDVI over most of the continent. It is also clear that SPEI-HR shows higher correlations. The time series comparison between the area mean SPEI and NDVI is shown in Fig. 5c. Both SPEI-HR and SPEI-CRU show agreement with NDVI, with $R=0.54$ and $R=0.47$, respectively. In addition, the comparison between 6-month SPEI and NDVI for the entire data record was also calculated, with $R=0.24$ for SPEI-HR and $R=0.21$ for SPEI-CRU significant at $95 \%$ confidence level (Fig. A3). 


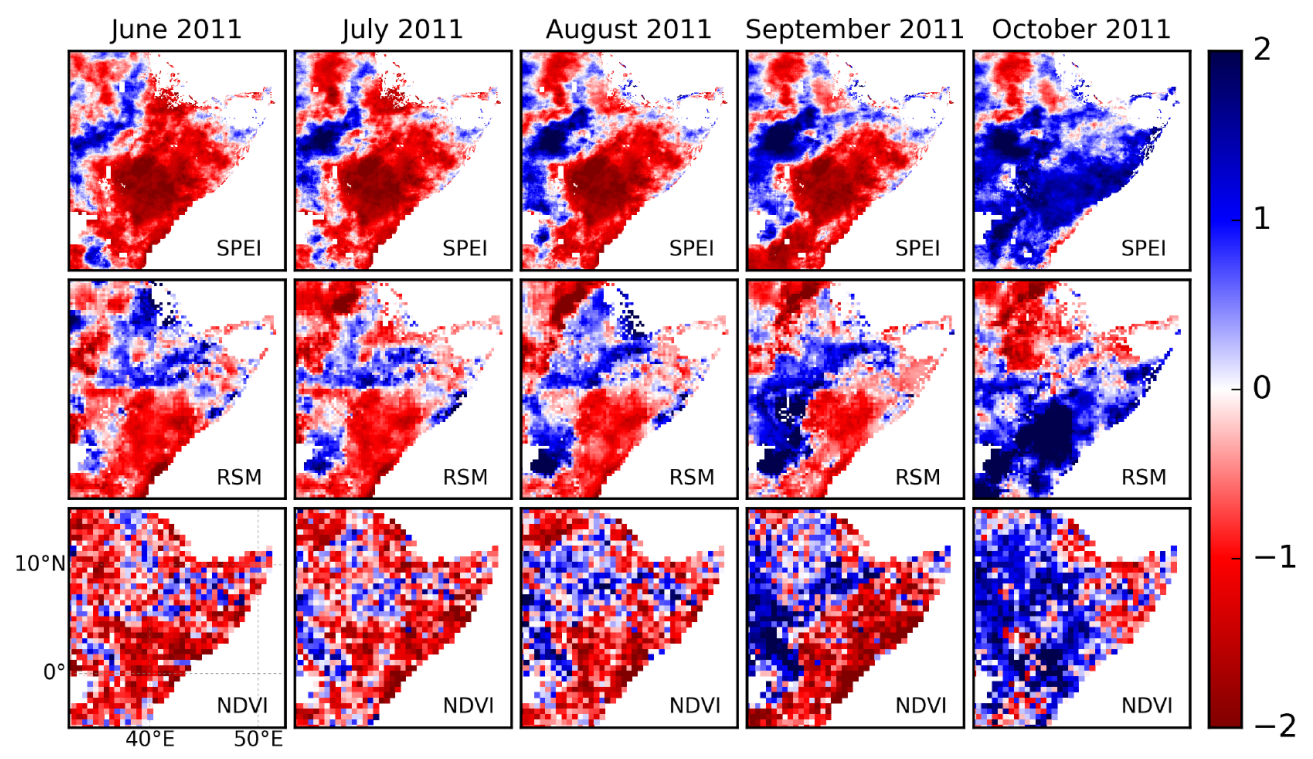

(a)

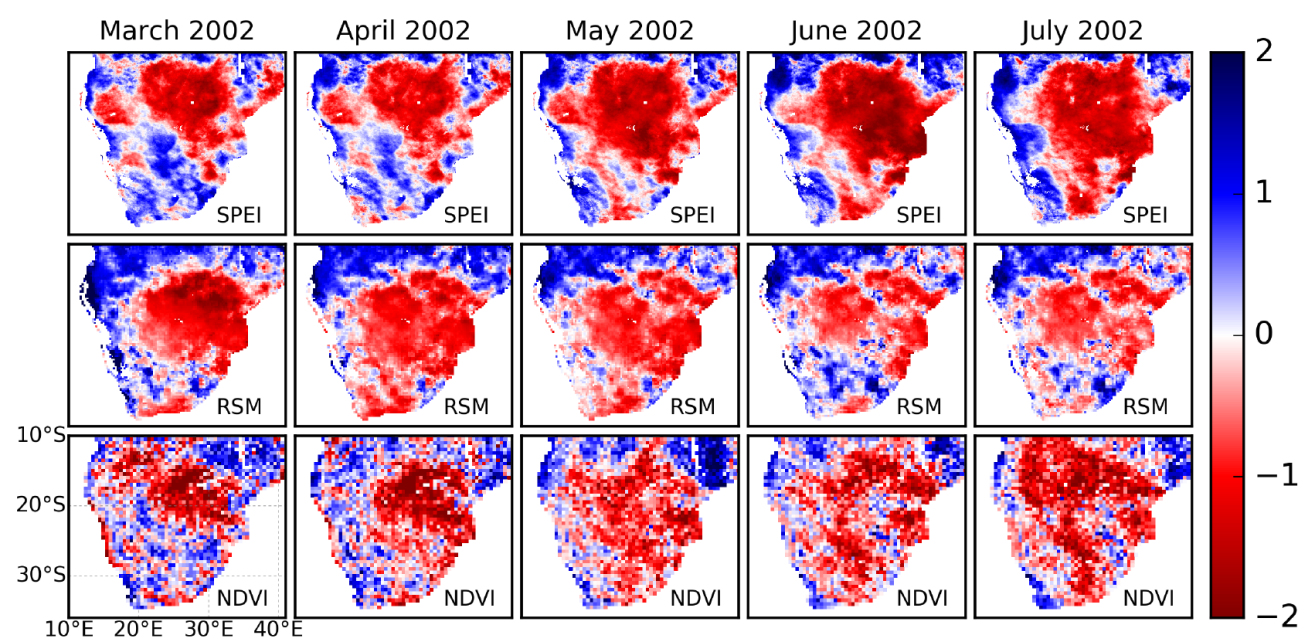

(b)

Figure 6. Evolution of the spatial patterns of 6-month SPEI-HR, NDVI and root zone soil moisture (RSM) during the 2011 East Africa drought (a) and 2002 southern Africa drought (b).

While these correlations are admittedly low, overall results suggest that the SPEI has a positive relation with NDVI, which is also reported by previous studies (e.g. Törnros and Menzel, 2014; Vicente-Serrano et al., 2018). The lower correlations against NDVI than against RSM are likely due to complex physiological processes associated with vegetation and the fact that ecosystem state is driven by multiple variables other than water availability (Nemani et al., 2003). Furthermore, there are also clearly documented lags between precipitation and NDVI, with NDVI time series typically peaking 1 or even 2 months after the period of maximum rainfall (Funk and Brown, 2006). Finally, Table 3 summa- rizes the correlation between SPEI and NDVI at different timescales. Compared with the results presented in Table 2 for RSM, the correlation with NDVI shown in Table 3 is also generally lower, and the highest correlations appear between 9- and 24-month SPEI $(R>0.5)$.

Altogether, the comparisons between SPEI and RSM and between SPEI and NDVI indirectly indicate the validity of the generated SPEI datasets. Therefore, the generated highresolution SPEI-HR from satellite products has the potential to improve upon the state of the art of drought assessment over Africa. 


\subsection{Patterns of SPEI, RSM and NDVI during specific drought events}

Most of Africa has suffered severe droughts in past decades (Naumann et al., 2014; Blamey et al., 2018). Among them, the 2011 East Africa drought (Anderson et al., 2012; AghaKouchak, 2015) and 2002 southern Africa drought (Masih et al., 2014) were extremely severe and had devastating effects on the natural and socioeconomic environment. Taking these two events as case studies, the spatial patterns of the newly developed high-resolution 6-month SPEI-HR are analysed, together with the variability in NDVI and RSM. Figure 6a, b show the evolution of 6-month SPEI, NDVI and RSM during the 2011 East Africa and the 2002 southern Africa drought, respectively. The 6-month periods end in the named month, with the 6-month June 2011 SPEI values based on data for January to June. In general, these three variables reflect the progressive dry-out during the events. For example, strong, severe drought is revealed by the SPEI with values less than -1.5 , coinciding with a decline in NDVI and RSM from June to September 2011 over East Africa; the drought was offset in October. Similarly, dry and wet conditions variations during the 2002 southern Africa drought were also captured by the three variables. Despite differences over space and time, results here demonstrate that the generated SPEI-HR captures the main drought conditions that are reflected by negative anomalies in NDVI and RSM and can thus be used to study local drought-related processes and societal impacts in Africa.

\section{Data availability}

The high-resolution SPEI dataset is publicly available from the Centre for Environmental Data Analysis (CEDA) from the following link: https://doi.org/10.5285/bbdfd09a04304158b366777eba0d2aeb (Peng et al., 2019a). It covers the whole of Africa at a monthly temporal resolution and $5 \mathrm{~km}$ spatial resolution from 1981 to 2016 and is provided with geographic latitude-longitude projection and NetCDF format.

\section{Conclusions}

The study presents a newly generated high-resolution SPEI dataset (SPEI-HR) over Africa. The dataset is produced from satellite-based CHIRPS precipitation and GLEAM potential evaporation and covers the entire African continent over the time period from 1981 to 2016 with a spatial resolution of $5 \mathrm{~km}$. The accumulated SPEI, ranging from 1 to 48 months, is provided to facilitate applications from meteorological to hydrological droughts. The SPEI-HR was compared with widely used coarse-resolution SPEI data (SPEICRU), GIMMS NDVI and GLEAM root zone soil moisture to investigate its capability for drought detection. In general, the SPEI-HR has good correlation with SPEI-CRU temporally and spatially. They both agree well with NDVI and root zone soil moisture, although SPEI-HR displays higher correlations overall. These results indicate the validity and advantage of the newly developed high-resolution SPEI-HR dataset, and its unprecedentedly high spatial resolution offers important advantages for drought monitoring and assessment at district and river basin level in Africa. 
Appendix A
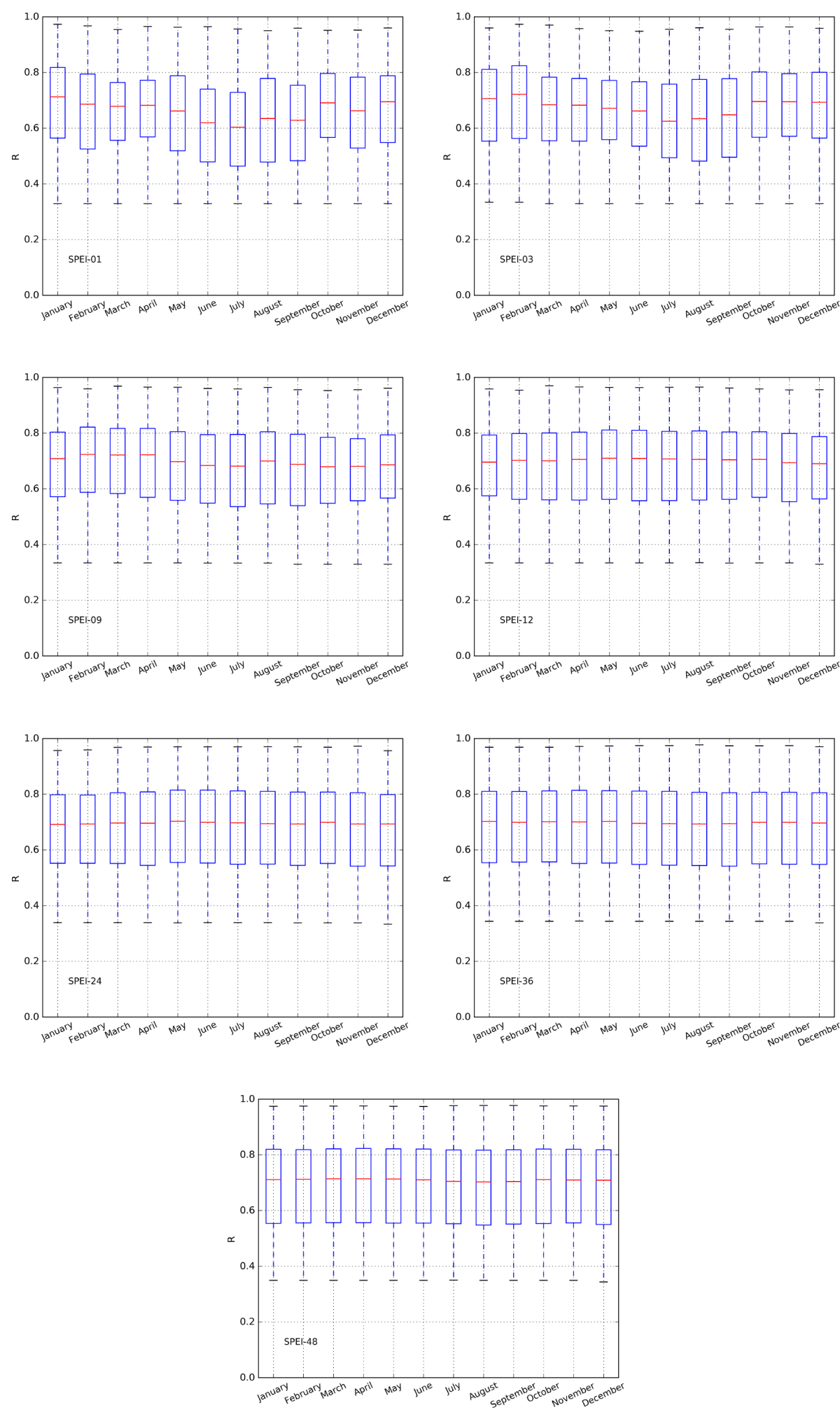

Figure A1. Box plots of the correlation $(p<0.05)$ between SPEI-HR and SPEI-CRU for each month and the entire monthly record. 

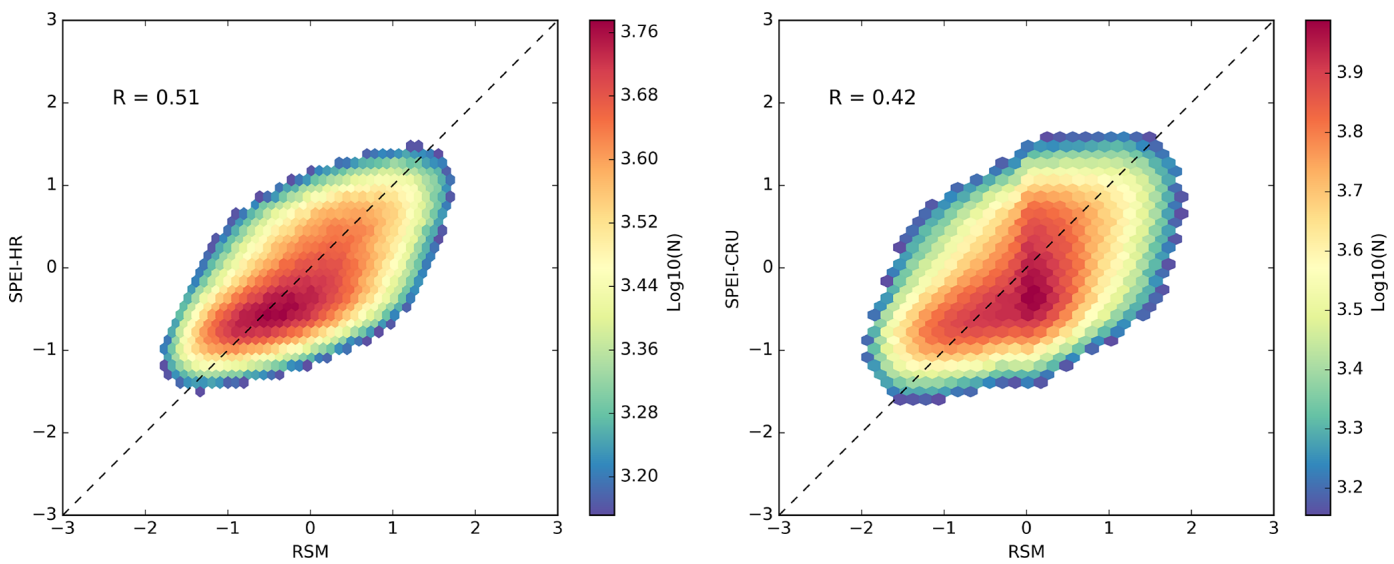

Figure A2. Scatter plots between 6-month SPEI and RSM for the entire data record. $R$ is correlation coefficient with $p<0.05$, and the colours denote the occurrence frequency of values.
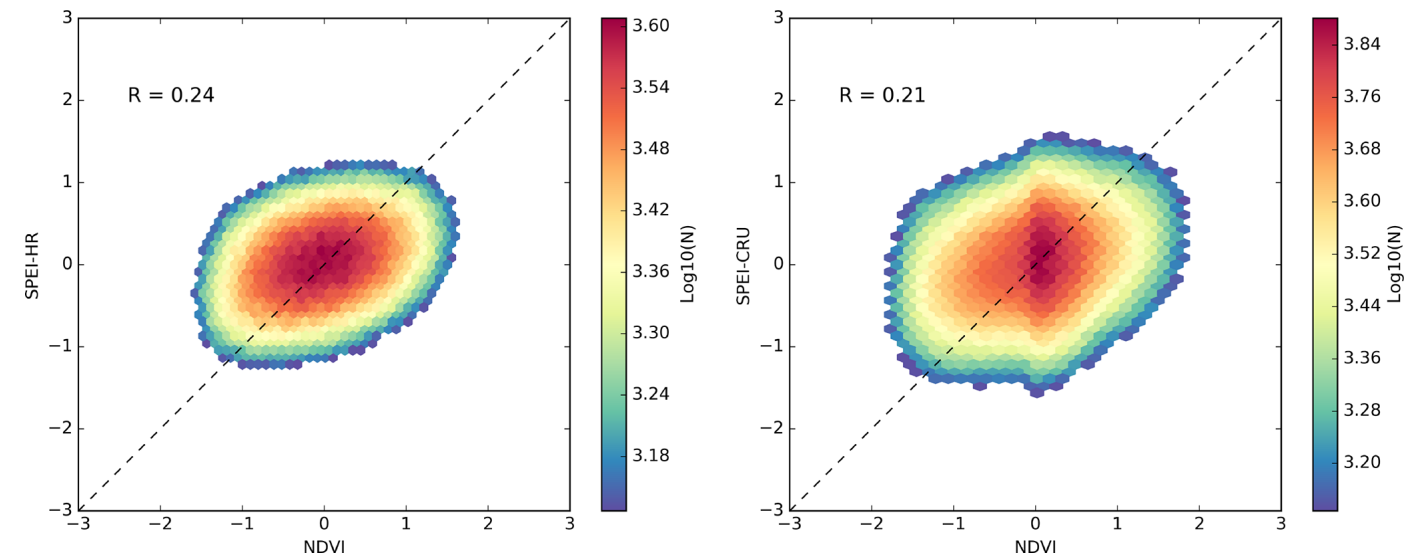

Figure A3. Scatter plots between 6-month SPEI and NDVI for the entire data record. $R$ is correlation coefficient with $p<0.05$, and the colours denote the occurrence frequency of values. 
Author contributions. JP developed the processing algorithm, generated the dataset and drafted the manuscript. DGM and CF produced the GLEAM and CHIRPS data as input. SD, FH, ED and TL supported the generation of the dataset and the analysis of the results. All authors contributed to the discussion, review and revision of this paper.

Competing interests. The authors declare that they have no conflict of interest.

Acknowledgements. This work is supported by the UK Space Agency's International Partnership Programme (417000001429). Diego G. Miralles acknowledges funding from the European Research Council (ERC) under grant agreement no. 715254 (DRY-2DRY). Simon Dadson is also funded by the Natural Environment Research Council (NE/M020339/1). Chris Funk is supported by the U.S. Geological Survey's Drivers of Drought program and NASA Harvest Program grant Z60592017.

Financial support. This research has been supported by the UK Space Agency's International Partnership Programme (grant no. 417000001429).

Review statement. This paper was edited by Alexander Gelfan and reviewed by two anonymous referees.

\section{References}

Aadhar, S. and Mishra, V.: High-resolution near real-time drought monitoring in South Asia, Scientific Data, 4, 170145, https://doi.org/10.1038/sdata.2017.145, 2017.

Adler, R. F., Huffman, G. J., Chang, A., Ferraro, R., Xie, P.-P., Janowiak, J., Rudolf, B., Schneider, U., Curtis, S., Bolvin, D., Gruber, A., Susskind, J., Arkin, P., and Nelkin, E.: The Version-2 Global Precipitation Climatology Project (GPCP) Monthly Precipitation Analysis (1979-Present), J. Hydrometeorol., 4, 11471167, 2003.

AghaKouchak, A.: A multivariate approach for persistence-based drought prediction: Application to the 2010-2011 East Africa drought, J. Hydrol., 526, 127-135, 2015.

AghaKouchak, A., Farahmand, A., Melton, F. S., Teixeira, J., Anderson, M. C., Wardlow, B. D., and Hain, C. R.: Remote sensing of drought: Progress, challenges and opportunities, Rev. Geophys., 53, 452-480, 2015.

Anderson, M. C., Hain, C., Wardlow, B., Pimstein, A., Mecikalski, J. R., and Kustas, W. P.: Evaluation of drought indices based on thermal remote sensing of evapotranspiration over the continental United States, J. Climate, 24, 2025-2044, 2011.

Anderson, W. B., Zaitchik, B. F., Hain, C. R., Anderson, M. C., Yilmaz, M. T., Mecikalski, J., and Schultz, L.: Towards an integrated soil moisture drought monitor for East Africa, Hydrol. Earth Syst. Sci., 16, 2893-2913, https://doi.org/10.5194/hess-162893-2012, 2012.
Anghileri, D., Li, C., Agaba, G., Kandel, M., Dash, J., Reeves, J., Lewis, L., Hill, C., and Sheffield, J.: Co-production and interdisciplinary research in the BRECcIA project: bringing together different expertise and actors for addressing water and food security challenges in sub-Saharan Africa, Geophys. Res. Abstr., EGU2019-14992, EGU General Assembly 2019, Vienna, Austria, 2019.

Arpe, K., Leroy, S. A. G., Lahijani, H., and Khan, V.: Impact of the European Russia drought in 2010 on the Caspian Sea level, Hydrol. Earth Syst. Sci., 16, 19-27, https://doi.org/10.5194/hess16-19-2012, 2012.

Awange, J. L., Khandu, Schumacher, M., Forootan, E., and Heck, B.: Exploring hydro-meteorological drought patterns over the Greater Horn of Africa (1979-2014) using remote sensing and reanalysis products, Adv. Water Res., 94, 45-59, 2016.

Bachmair, S., Stahl, K., Collins, K., Hannaford, J., Acreman, M., Svoboda, M., Knutson, C., Smith, K. H., Wall, N., and Fuchs, B.: Drought indicators revisited: the need for a wider consideration of environment and society, Wiley Interdisciplinary Reviews: Water, 3, 516-536, 2016.

Bachmair, S., Tanguy, M., Hannaford, J., and Stahl, K.: How well do meteorological indicators represent agricultural and forest drought across Europe?, Environ. Res. Lett., 13, 034042, https://doi.org/10.1088/1748-9326/aaafda, 2018.

Baudoin, M.-A., Vogel, C., Nortje, K., and Naik, M.: Living with drought in South Africa: lessons learnt from the recent El Niño drought period, Int. J. Disast. Risk Re., 23, 128-137, 2017.

Beck, H. E., McVicar, T. R., van Dijk, A. I., Schellekens, J., de Jeu, R. A., and Bruijnzeel, L. A.: Global evaluation of four AVHRRNDVI data sets: Intercomparison and assessment against Landsat imagery, Remote Sens. Environ., 115, 2547-2563, 2011.

Beck, H. E., van Dijk, A. I. J. M., Levizzani, V., Schellekens, J., Miralles, D. G., Martens, B., and de Roo, A.: MSWEP: 3hourly $0.25^{\circ}$ global gridded precipitation (1979-2015) by merging gauge, satellite, and reanalysis data, Hydrol. Earth Syst. Sci. 21, 589-615, https://doi.org/10.5194/hess-21-589-2017, 2017.

Becker, A., Finger, P., Meyer-Christoffer, A., Rudolf, B., Schamm, K., Schneider, U., and Ziese, M.: A description of the global land-surface precipitation data products of the Global Precipitation Climatology Centre with sample applications including centennial (trend) analysis from 1901-present, Earth Syst. Sci. Data, 5, 71-99, https://doi.org/10.5194/essd-5-71-2013, 2013.

Beguería, S., Vicente-Serrano, S. M., and Angulo-Martínez, M.: A multiscalar global drought dataset: the SPEIbase: a new gridded product for the analysis of drought variability and impacts, B. Am. Meteorol. Soc., 91, 1351-1356, 2010.

Beguería, S., Vicente-Serrano, S. M., Reig, F., and Latorre, B.: Standardized precipitation evapotranspiration index (SPEI) revisited: parameter fitting, evapotranspiration models, tools, datasets and drought monitoring, Int. J. Climatol., 34, 3001-3023, 2014.

Blamey, R. C., Kolusu, S. R., Mahlalela, P., Todd, M. C., and Reason, C. J. C.: The role of regional circulation features in regulating El Niño climate impacts over southern Africa: A comparison of the 2015/2016 drought with previous events, Int. J. Climatol., 38, 4276-4295, https://doi.org/10.1002/joc.5668, 2018.

Chadwick, R., Good, P., Martin, G., and Rowell, D. P.: Large rainfall changes consistently projected over substantial areas of tropical land, Nat. Clim. Change, 6, 177-181, https://doi.org/10.1038/nclimate2805, 2015. 
Chen, T., Werf, G. R., Jeu, R. A. M., Wang, G., and Dolman, A. J.: A global analysis of the impact of drought on net primary productivity, Hydrol. Earth Syst. Sci., 17, 3885-3894, https://doi.org/10.5194/hess-17-3885-2013, 2013.

Crausbay, S. D., Ramirez, A. R., Carter, S. L., Cross, M. S., Hall, K. R., Bathke, D. J., Betancourt, J. L., Colt, S., Cravens, A. E., and Dalton, M. S.: Defining ecological drought for the twenty-first century, B. Am. Meteorol. Soc., 98, 2543-2550, 2017.

Dadson, S. J., Lopez, H. P., Peng, J., and Vora, S.: Hydroclimatic Extremes and Climate Change, Water Science, Policy, and Management: A Global Challenge, Wiley, 11-28, https://doi.org/10.1002/9781119520627.ch2, 2019.

Delworth, T. L., Zeng, F., Rosati, A., Vecchi, G. A., and Wittenberg, A. T.: A Link between the Hiatus in Global Warming and North American Drought, J. Climate, 28, 3834-3845, 2015.

Deo, R. C., Byun, H.-R., Adamowski, J. F., and Begum, K.: Application of effective drought index for quantification of meteorological drought events: a case study in Australia, Theor. Appl. Climatol., 128, 359-379, 2017.

Ding, Y., Hayes, M. J., and Widhalm, M.: Measuring economic impacts of drought: a review and discussion, Disaster Prev. Manag., 20, 434-446, 2011.

Dinku, T., Funk, C., Peterson, P., Maidment, R., Tadesse, T., Gadain, H., and Ceccato, P.: Validation of the CHIRPS satellite rainfall estimates over eastern Africa, Q. J. Roy. Meteor. Soc., 144, 292-312, https://doi.org/10.1002/qj.3244, 2018.

Duan, Z., Liu, J., Tuo, Y., Chiogna, G., and Disse, M.: Evaluation of eight high spatial resolution gridded precipitation products in Adige Basin (Italy) at multiple temporal and spatial scales, Sci. Total Environ., 573, 1536-1553, 2016.

Fan, Y. and Van den Dool, H.: A global monthly land surface air temperature analysis for 1948-present, J. Geophys. Res.-Atmos., 113, D01103, https://doi.org/10.1029/2007JD008470, 2008.

Fisher, J. B., Melton, F., Middleton, E., Hain, C., Anderson, M., Allen, R., McCabe, M. F., Hook, S., Baldocchi, D., and Townsend, P. A.: The future of evapotranspiration: Global requirements for ecosystem functioning, carbon and climate feedbacks, agricultural management, and water resources, Water Resour. Res., 53, 2618-2626, 2017.

Forzieri, G., Alkama, R., Miralles, D. G., and Cescatti, A.: Satellites reveal contrasting responses of regional climate to the widespread greening of Earth, Science, 356, 1180-1184, 2017.

Friedl, M. A., Sulla-Menashe, D., Tan, B., Schneider, A., Ramankutty, N., Sibley, A., and Huang, X.: MODIS Collection 5 global land cover: Algorithm refinements and characterization of new datasets, Remote Sens. Environ., 114, 168-182, 2010.

Funk, C., Peterson, P., Landsfeld, M., Pedreros, D., Verdin, J., Shukla, S., Husak, G., Rowland, J., Harrison, L., Hoell, A., and Michaelsen, J.: The climate hazards infrared precipitation with stations - a new environmental record for monitoring extremes, Scientific Data, 2, 150066, https://doi.org/10.1038/sdata.2015.66, 2015a.

Funk, C., Verdin, A., Michaelsen, J., Peterson, P., Pedreros, D., and Husak, G.: A global satellite-assisted precipitation climatology, Earth Syst. Sci. Data, 7, 275-287, https://doi.org/10.5194/essd7-275-2015, 2015b.

Funk, C., Harrison, L., Shukla, S., Pomposi, C., Galu, G., Korecha, D., Husak, G., Magadzire, T., Davenport, F., and Hillbruner, C.: Examining the role of unusually warm Indo-Pacific sea-surface temperatures in recent African droughts, Q. J. Roy. Meteor. Soc., 144, 360-383, 2018.

Funk, C. C. and Brown, M. E.: Intra-seasonal NDVI change projections in semi-arid Africa, Remote Sens. Environ., 101, 249-256, 2006.

Funk, C. C., Peterson, P. J., Landsfeld, M. F., Pedreros, D. H., Verdin, J. P., Rowland, J. D., Romero, B. E., Husak, G. J., Michaelsen, J. C., and Verdin, A. P.: A quasi-global precipitation time series for drought monitoring, US Geological Survey Data Series, 832, 1-12, https://doi.org/10.3133/ds832, 2014.

García-Herrera, R., Díaz, J., Trigo, R. M., Luterbacher, J., and Fischer, E. M.: A review of the European summer heat wave of 2003, Crit. Rev. Env. Sci. Tec., 40, 267-306, 2010.

Gebremeskel, G., Tang, Q., Sun, S., Huang, Z., Zhang, X., and Liu, X.: Droughts in East Africa: Causes, impacts and resilience, Earth-Sci. Rev., 193, 146-161, https://doi.org/10.1016/j.earscirev.2019.04.015, 2019.

Greenwood, S., Ruiz-Benito, P., Martínez-Vilalta, J., Lloret, F., Kitzberger, T., Allen, C. D., Fensham, R., Laughlin, D. C., Kattge, J., and Bönisch, G.: Tree mortality across biomes is promoted by drought intensity, lower wood density and higher specific leaf area, Ecol. Lett., 20, 539-553, 2017.

Greve, P., Orlowsky, B., Mueller, B., Sheffield, J., Reichstein, M., and Seneviratne, S. I.: Global assessment of trends in wetting and drying over land, Nat. Geosci., 7, 716-721, https://doi.org/10.1038/ngeo22472014, 2014.

Griffin, D. and Anchukaitis, K. J.: How unusual is the 2012-2014 California drought?, Geophys. Res. Lett., 41, 9017-9023, 2014.

Guo, H., Bao, A., Liu, T., Ndayisaba, F., He, D., Kurban, A., and De Maeyer, P.: Meteorological drought analysis in the Lower Mekong Basin using satellite-based long-term CHIRPS product, Sustainability, 9, 901, https://doi.org/10.3390/su9060901, 2017.

Harris, I., Jones, P. D., Osborn, T. J., and Lister, D. H.: Updated high-resolution grids of monthly climatic observations - the CRU TS3.10 Dataset, Int. J. Climatol., 34, 623-642, 2014.

Heim Jr., R. R.: A review of twentieth-century drought indices used in the United States, B. Am. Meteorol. Soc., 83, 1149-1165, 2002.

Isbell, F., Craven, D., Connolly, J., Loreau, M., Schmid, B., Beierkuhnlein, C., Bezemer, T. M., Bonin, C., Bruelheide, H., de Luca, E., Ebeling, A., Griffin, J. N., Guo, Q., Hautier, Y., Hector, A., Jentsch, A., Kreyling, J., Lanta, V., Manning, P., Meyer, S. T., Mori, A. S., Naeem, S., Niklaus, P. A., Polley, H. W., Reich, P. B., Roscher, C., Seabloom, E. W., Smith, M. D., Thakur, M. P., Tilman, D., Tracy, B. F., van der Putten, W. H., van Ruijven, J., Weigelt, A., Weisser, W. W., Wilsey, B., and Eisenhauer, N.: Biodiversity increases the resistance of ecosystem productivity to climate extremes, Nature, 526, 574-577, https://doi.org/10.1038/nature15374, 2015.

Jägermeyr, J., Gerten, D., Schaphoff, S., Heinke, J., Lucht, W., and Rockström, J.: Integrated crop water management might sustainably halve the global food gap, Environ. Res. Lett., 11, 025002, https://doi.org/10.1088/1748-9326/11/2/025002, 2016.

Jiang, P., Liu, H., Piao, S., Ciais, P., Wu, X., Yin, Y., and Wang, H.: Enhanced growth after extreme wetness compensates for post-drought carbon loss in dry forests, Nat. Commun., 10, 19, https://doi.org/10.1038/s41467-018-08229-z, 2019. 
Keyantash, J. and Dracup, J. A.: The quantification of drought: an evaluation of drought indices, B. Am. Meteorol. Soc., 83, 11671180, 2002.

Kumar, R., Musuuza, J. L., Van Loon, A. F., Teuling, A. J., Barthel, R., Ten Broek, J., Mai, J., Samaniego, L., and Attinger, S.: Multiscale evaluation of the Standardized Precipitation Index as a groundwater drought indicator, Hydrol. Earth Syst. Sci., 20, 1117-1131, https://doi.org/10.5194/hess-20-1117-2016, 2016.

Lian, X., Piao, S., Huntingford, C., Li, Y., Zeng, Z., Wang, X., Ciais, P., McVicar, T. R., Peng, S., Ottlé, C., Yang, H., Yang, Y., Zhang, Y., and Wang, T.: Partitioning global land evapotranspiration using CMIP5 models constrained by observations, Nat. Clim. Change, 8, 640-646, 2018.

Lloyd-Hughes, B.: The impracticality of a universal drought definition, Theor. Appl. Climatol., 117, 607-611, 2014.

Maidment, R. I., Allan, R. P., and Black, E.: Recent observed and simulated changes in precipitation over Africa, Geophys. Res. Lett., 42, 8155-8164, 2015.

Mann, M. E. and Gleick, P. H.: Climate change and California drought in the 21 st century, P. Natl. Acad. Sci. USA, 112, 38583859, 2015.

Martens, B., Miralles, D. G., Lievens, H., van der Schalie, R., de Jeu, R. A. M., Fernández-Prieto, D., Beck, H. E., Dorigo, W. A., and Verhoest, N. E. C.: GLEAM v3: satellite-based land evaporation and root-zone soil moisture, Geosci. Model Dev., 10, 19031925, https://doi.org/10.5194/gmd-10-1903-2017, 2017.

Marvel, K., Cook, B. I., Bonfils, C. J., Durack, P. J., Smerdon, J. E., and Williams, A. P.: Twentieth-century hydroclimate changes consistent with human influence, Nature, 569, 59-65, https://doi.org/10.1038/s41586-019-1149-8, 2019.

Masih, I., Maskey, S., Mussá, F. E. F., and Trambauer, P.: A review of droughts on the African continent: a geospatial and long-term perspective, Hydrol. Earth Syst. Sci., 18, 3635-3649, https://doi.org/10.5194/hess-18-3635-2014, 2014.

McKee, T. B., Doesken, N. J., and Kleist, J.: The relationship of drought frequency and duration to time scales, in: Proceedings of the 8th Conference on Applied Climatology, 17, 179-183, 1993.

Miralles, D. G., Holmes, T. R. H., De Jeu, R. A. M., Gash, J. H., Meesters, A. G. C. A., and Dolman, A. J.: Global land-surface evaporation estimated from satellite-based observations, Hydrol. Earth Syst. Sci., 15, 453-469, https://doi.org/10.5194/hess-15453-2011, 2011.

Miralles, D. G., Van Den Berg, M. J., Gash, J. H., Parinussa, R. M., De Jeu, R. A., Beck, H. E., Holmes, T. R., Jiménez, C., Verhoest, N. E., and Dorigo, W. A.: El Niño-La Niña cycle and recent trends in continental evaporation, Nat. Clim. Change, 4, 122-126, https://doi.org/10.1038/nclimate2068, 2014.

Mishra, A. K. and Singh, V. P.: A review of drought concepts, J. Hydrol., 391, 202-216, 2010.

Mo, K. C., Long, L. N., Xia, Y., Yang, S. K., Schemm, J. E., and Ek, M.: Drought Indices Based on the Climate Forecast System Reanalysis and Ensemble NLDAS, J. Hydrometeorol., 12, 181205, 2011.

Mu, Q., Zhao, M., Kimball, J. S., McDowell, N. G., and Running, S. W.: A remotely sensed global terrestrial drought severity index, B. Am. Meteorol. Soc., 94, 83-98, 2013.

Mukherjee, S., Mishra, A., and Trenberth, K. E.: Climate change and drought: a perspective on drought indices, Current Climate Change Reports, 4, 145-163, 2018.
Muller, M.: Cape Town's drought: don't blame climate change, Nature, 559, 174-176, https://doi.org/10.1038/d41586-018-05649$1,2018$.

Naumann, G., Dutra, E., Barbosa, P., Pappenberger, F., Wetterhall, F., and Vogt, J. V.: Comparison of drought indicators derived from multiple data sets over Africa, Hydrol. Earth Syst. Sci., 18, 1625-1640, https://doi.org/10.5194/hess-18-1625-2014, 2014.

Naumann, G., Alfieri, L., Wyser, K., Mentaschi, L., Betts, R. A., Carrao, H., Spinoni, J., Vogt, J., and Feyen, L.: Global Changes in Drought Conditions Under Different Levels of Warming, Geophys. Res. Lett., 45, 3285-3296, 2018.

Nemani, R. R., Keeling, C. D., Hashimoto, H., Jolly, W. M., Piper, S. C., Tucker, C. J., Myneni, R. B., and Running, S. W.: ClimateDriven Increases in Global Terrestrial Net Primary Production from 1982 to 1999, Science, 300, 1560-1563, 2003.

Nicholson, S. E.: A detailed look at the recent drought situation in the Greater Horn of Africa, J. Arid Environ., 103, 71-79, 2014.

Nicholson, S. E.: The ITCZ and the seasonal cycle over equatorial Africa, B. Am. Meteorol. Soc., 99, 337-348, 2018.

Panu, U. and Sharma, T.: Challenges in drought research: some perspectives and future directions, Hydrolog. Sci. J., 47, S19-S30, 2002.

Peña-Gallardo, M., Vicente-Serrano, S., Camarero, J., Gazol, A., Sánchez-Salguero, R., Domínguez-Castro, F., El Kenawy, A., Beguería-Portugés, S., Gutiérrez, E., and de Luis, M.: Drought Sensitiveness on Forest Growth in Peninsular Spain and the Balearic Islands, Forests, 9, 524, https://doi.org/10.3390/f9090524, 2018a.

Peña-Gallardo, M., Vicente-Serrano, S. M., Domínguez-Castro, F., Quiring, S., Svoboda, M., Beguería, S., and Hannaford, J.: Effectiveness of drought indices in identifying impacts on major crops across the USA, Clim. Res., 75, 221-240, 2018b.

Peng, J., Dadson, S., Hirpa, F., Dyer, E., Lees, T., Miralles, D. G., Vicente-Serrano, S. M. V.-S., and Funk, C.: High resolution Standardized Precipitation Evapotranspiration Index (SPEI) dataset for Africa, Centre for Environmental Data Analysis, https://doi.org/10.5285/bbdfd09a04304158b366777eba0d2aeb, 2019a.

Peng, J., Dadson, S., Leng, G., Duan, Z., Jagdhuber, T., Guo, W., and Ludwig, R.: The impact of the Madden-Julian Oscillation on hydrological extremes, J. Hydrol., 571, 142-149, 2019b.

Peng, J., Muller, J.-P., Blessing, S., Giering, R., Danne, O., Gobron, N., Kharbouche, S., Ludwig, R., Müller, B., and Leng, G.: Can We Use Satellite-Based FAPAR to Detect Drought?, Sensors, 19, 3662, https://doi.org/10.3390/s19173662, 2019c.

Pinzon, J. E. and Tucker, C. J.: A non-stationary 1981-2012 AVHRR NDVI3g time series, Remote Sensing, 6, 6929-6960, 2014.

Pozzi, W., Sheffield, J., Stefanski, R., Cripe, D., Pulwarty, R., Vogt, J. V., Heim Jr., R. R., Brewer, M. J., Svoboda, M., and Westerhoff, R.: Toward global drought early warning capability: Expanding international cooperation for the development of a framework for monitoring and forecasting, B. Am. Meteorol. Soc., 94, 776-785, 2013.

Richard, W., Sonia, I. S., Martin, H., Jinfeng, C., Philippe, C., Delphine, D., Joshua, E., Christian, F., Simon, N. G., Lukas, G., Alexandra-Jane, H., Thomas, H., Akihiko, I., Nikolay, K., Hyungjun, K., Guoyong, L., Junguo, L., Xingcai, L., Yoshimitsu, M., Catherine, M., Christoph, M., Hannes Müller, S., Kazuya, 
N., Rene, O., Yadu, P., Thomas, A. M. P., Yusuke, S., Sibyll, S., Erwin, S., Justin, S., Tobias, S., Joerg, S., Qiuhong, T., Wim, T., Yoshihide, W., Xuhui, W., Graham, P. W., Hong, Y., and Tian, Z.: Evapotranspiration simulations in ISIMIP2a - Evaluation of spatio-temporal characteristics with a comprehensive ensemble of independent datasets, Environ. Res. Lett., 13, 075001, https://doi.org/10.1088/1748-9326/aac4bb, 2018.

Rivera, J. A., Marianetti, G., and Hinrichs, S.: Validation of CHIRPS precipitation dataset along the Central Andes of Argentina, Atmos. Res., 213, 437-449, 2018.

Rojas, O., Vrieling, A., and Rembold, F.: Assessing drought probability for agricultural areas in Africa with coarse resolution remote sensing imagery, Remote Sens. Environ., 115, 343-352, 2011.

Schneider, U., Ziese, M., Meyer-Christoffer, A., Finger, P., Rustemeier, E., and Becker, A.: The new portfolio of global precipitation data products of the Global Precipitation Climatology Centre suitable to assess and quantify the global water cycle and resources, P. Int. Ass. Hydrol. Sci., 374, 29-34, 2016.

Schwalm, C. R., Anderegg, W. R. L., Michalak, A. M., Fisher, J. B., Biondi, F., Koch, G., Litvak, M., Ogle, K., Shaw, J. D., Wolf, A., Huntzinger, D. N., Schaefer, K., Cook, R., Wei, Y., Fang, Y., Hayes, D., Huang, M., Jain, A., and Tian, H.: Global patterns of drought recovery, Nature, 548, 202-205, https://doi.org/10.1038/nature23021, 2017.

Sheffield, J., Wood, E. F., Chaney, N., Guan, K., Sadri, S., Yuan, X., Olang, L., Amani, A., Ali, A., and Demuth, S.: A drought monitoring and forecasting system for sub-Sahara African water resources and food security, B. Am. Meteorol. Soc., 95, 861-882, 2014.

Shukla, S., McNally, A., Husak, G., and Funk, C.: A seasonal agricultural drought forecast system for food-insecure regions of East Africa, Hydrol. Earth Syst. Sci., 18, 3907-3921, https://doi.org/10.5194/hess-18-3907-2014, 2014.

Spinoni, J., Naumann, G., Vogt, J. V., and Barbosa, P.: The biggest drought events in Europe from 1950 to 2012, J. Hydrol., 3, 509$524,2015$.

Sun, Q., Miao, C., AghaKouchak, A., and Duan, Q.: Century-scale causal relationships between global dry/wet conditions and the state of the Pacific and Atlantic Oceans, Geophys. Res. Lett., 43, 6528-6537, 2016.

Sun, S., Chen, H., Wang, G., Li, J., Mu, M., Yan, G., Xu, B., Huang, J., Wang, J., and Zhang, F.: Shift in potential evapotranspiration and its implications for dryness/wetness over Southwest China, J. Geophys. Res.-Atmos., 121, 9342-9355, 2016.

Sun, S., Chen, H., Li, J., Wei, J., Wang, G., Sun, G., Hua, W., Zhou, S., and Deng, P.: Dependence of 3-month Standardized Precipitation-Evapotranspiration Index dryness/wetness sensitivity on climatological precipitation over southwest China, Int. J. Climatol., 38, 4568-4578, 2018.

Swain, D. L., Tsiang, M., Haugen, M., Singh, D., Charland, A., Rajaratnam, B., and Diffenbaugh, N. S.: The extraordinary California drought of 2013/2014: Character, context, and the role of climate change, B. Am. Meteorol. Soc., 95, S3-S7, 2014.

Törnros, T. and Menzel, L.: Addressing drought conditions under current and future climates in the Jordan River region, Hydrol. Earth Syst. Sci., 18, 305-318, https://doi.org/10.5194/hess-18305-2014, 2014.
Toté, C., Patricio, D., Boogaard, H., Van Der Wijngaart, R., Tarnavsky, E., and Funk, C.: Evaluation of satellite rainfall estimates for drought and flood monitoring in Mozambique, Remote Sensing, 7, 1758-1776, 2015.

Trambauer, P., Maskey, S., Winsemius, H., Werner, M., and Uhlenbrook, S.: A review of continental scale hydrological models and their suitability for drought forecasting in (sub-Saharan) Africa, Phys. Chem. Earth, 66, 16-26, 2013.

Trambauer, P., Dutra, E., Maskey, S., Werner, M., Pappenberger, F., van Beek, L. P. H., and Uhlenbrook, S.: Comparison of different evaporation estimates over the African continent, Hydrol. Earth Syst. Sci., 18, 193-212, https://doi.org/10.5194/hess-18193-2014, 2014.

Um, M.-J., Kim, Y., Park, D., and Kim, J.: Effects of different reference periods on drought index (SPEI) estimations from 1901 to 2014, Hydrol. Earth Syst. Sci., 21, 4989-5007, https://doi.org/10.5194/hess-21-4989-2017, 2017.

van der Schrier, G., Barichivich, J., Briffa, K., and Jones, P.: A scPDSI-based global data set of dry and wet spells for 19012009, J. Geophys. Res.-Atmos., 118, 4025-4048, 2013.

van Dijk, A. I., Beck, H. E., Crosbie, R. S., de Jeu, R. A., Liu, Y. Y., Podger, G. M., Timbal, B., and Viney, N. R.: The Millennium Drought in southeast Australia (2001-2009): Natural and human causes and implications for water resources, ecosystems, economy, and society, Water Resour. Res., 49, 1040-1057, 2013.

Van Loon, A. F.: Hydrological drought explained, Wiley Interdisciplinary Reviews: Water, 2, 359-392, 2015.

Vicente-Serrano, S.: Foreword: Drought complexity and assessment under climate change conditions, Cuadernos de Investigación Geográfica, 42, 7-11, 2016.

Vicente-Serrano, S. M.: Evaluating the impact of drought using remote sensing in a Mediterranean, semi-arid region, Nat. Hazards, 40, 173-208, 2007.

Vicente-Serrano, S. M. and Beguería, S.: Comment on "Candidate distributions for climatological drought indices (SPI and SPEI)" by James H. Stagge et al, Int. J. Climatol., 36, 2120-2131, 2016.

Vicente-Serrano, S. M., Beguería, S., and López-Moreno, J. I.: A multiscalar drought index sensitive to global warming: the standardized precipitation evapotranspiration index, J. Climate, 23, 1696-1718, 2010.

Vicente-Serrano, S. M., Beguería, S., Gimeno, L., Eklundh, L., Giuliani, G., Weston, D., El Kenawy, A., López-Moreno, J. I., Nieto, R., and Ayenew, T.: Challenges for drought mitigation in Africa: The potential use of geospatial data and drought information systems, Appl. Geogr., 34, 471-486, 2012 a.

Vicente-Serrano, S. M., Beguería, S., Lorenzo-Lacruz, J., Camarero, J. J., López-Moreno, J. I., Azorin-Molina, C., Revuelto, J., Morán-Tejeda, E., and Sanchez-Lorenzo, A.: Performance of Drought Indices for Ecological, Agricultural, and Hydrological Applications, Earth Interact., 16, 1-27, 2012b.

Vicente-Serrano, S. M., Gouveia, C., Camarero, J. J., Beguería, S., Trigo, R., López-Moreno, J. I., Azorín-Molina, C., Pasho, E., Lorenzo-Lacruz, J., Revuelto, J., Morán-Tejeda, E., and SanchezLorenzo, A.: Response of vegetation to drought time-scales across global land biomes, P. Natl. Acad. Sci. USA, 110, 52-57, 2013.

Vicente-Serrano, S. M., García-Herrera, R., Barriopedro, D., Azorin-Molina, C., López-Moreno, J. I., Martín-Hernández, N., Tomás-Burguera, M., Gimeno, L., and Nieto, R.: The Westerly 
Index as complementary indicator of the North Atlantic oscillation in explaining drought variability across Europe, Clim. Dynam., 47, 845-863, 2016.

Vicente-Serrano, S. M., Tomas-Burguera, M., Beguería, S., Reig, F., Latorre, B., Peña-Gallardo, M., Luna, M. Y., Morata, A., and González-Hidalgo, J. C.: A high resolution dataset of drought indices for Spain, Data, 2, 22, https://doi.org/10.3390/data2030022, 2017.

Vicente-Serrano, S. M., Miralles, D. G., Domínguez-Castro, F., Azorin-Molina, C., Kenawy, A. E., McVicar, T. R., TomásBurguera, M., Beguería, S., Maneta, M., and Peña-Gallardo, M.: Global Assessment of the Standardized Evapotranspiration Deficit Index (SEDI) for Drought Analysis and Monitoring, J. Climate, 31, 5371-5393, 2018.

von Hardenberg, J., Meron, E., Shachak, M., and Zarmi, Y.: Diversity of vegetation patterns and desertification, Phys. Rev. Lett., 87, 198101, https://doi.org/10.1103/PhysRevLett.87.19810, 2001.

Wang, H. and He, S.: The North China/Northeastern Asia Severe Summer Drought in 2014, J. Climate, 28, 6667-6681, 2015.

Wegren, S. K.: Food security and Russia's 2010 drought, Eurasian Geogr. Econ., 52, 140-156, 2011.

Wilhite, D. and Pulwarty, R.: Drought as Hazard: Understanding the Natural and Social Context, in: Drought and Water Crises: Integrating Science, Management, and Policy, CRC Press, 2017.

Wilhite, D. A., Svoboda, M. D., and Hayes, M. J.: Understanding the complex impacts of drought: A key to enhancing drought mitigation and preparedness, Water Resour. Manage., 21, 763-774, 2007.
Xu, Y., Wang, L., Ross, K. W., Liu, C., and Berry, K.: Standardized Soil Moisture Index for Drought Monitoring Based on Soil Moisture Active Passive Observations and 36 Years of North American Land Data Assimilation System Data: A Case Study in the Southeast United States, Remote Sensing, 10, p. 301, https://doi.org/10.3390/rs10020301, 2018.

Yuan, X., Wood, E. F., Chaney, N. W., Sheffield, J., Kam, J., Liang, M., and Guan, K.: Probabilistic Seasonal Forecasting of African Drought by Dynamical Models, J. Hydrometeorol., 14, 17061720, 2013.

Zambrano-Bigiarini, M., Nauditt, A., Birkel, C., Verbist, K., and Ribbe, L.: Temporal and spatial evaluation of satellite-based rainfall estimates across the complex topographical and climatic gradients of Chile, Hydrol. Earth Syst. Sci., 21, 1295-1320, https://doi.org/10.5194/hess-21-1295-2017, 2017.

Zhan, S., Song, C., Wang, J., Sheng, Y., and Quan, J.: A global assessment of terrestrial evapotranspiration increase due to surface water area change, Earth's future, 7, 266-282, 2019.

Zhao, M., A, G., Velicogna, I., and Kimball, J. S.: A Global Gridded Dataset of GRACE Drought Severity Index for 2002-14: Comparison with PDSI and SPEI and a Case Study of the Australia Millennium Drought, J. Hydrometeorol., 18, 2117-2129, 2017.

Zhou, Q., Leng, G., and Peng, J.: Recent Changes in the Occurrences and Damages of Floods and Droughts in the United States, Water, 10, 1109, https://doi.org/10.3390/w10091109, 2018.

Ziese, M., Schneider, U., Meyer-Christoffer, A., Schamm, K., Vido, J., Finger, P., Bissolli, P., Pietzsch, S., and Becker, A.: The GPCC Drought Index - a new, combined and gridded global drought index, Earth Syst. Sci. Data, 6, 285-295, https://doi.org/10.5194/essd-6-285-2014, 2014. 